\title{
Curative treatment of oesophageal carcinoma: current options and future developments
}

\author{
Maria C Wolf ${ }^{*}$, Michael Stahl ${ }^{2}$, Bernd J Krause ${ }^{3,4}$, Luigi Bonavina ${ }^{5}$, Christiane Bruns ${ }^{6}$, Claus Belka ${ }^{1}$ and \\ Franz Zehentmayr ${ }^{1}$
}

\begin{abstract}
Since the 1980s major advances in surgery, radiotherapy and chemotherapy have established multimodal approaches as curative treatment options for oesophageal cancer. In addition the introduction of functional imaging modalities such as PET-CT created new opportunities for a more adequate patient selection and therapy response assessment.

The majority of oesophageal carcinomas are represented by two histologies: squamous cell carcinoma and adenocarcinoma. In recent years an epidemiological shift towards the latter was observed. From a surgical point of view, adenocarcinomas, which are usually located in the distal third of the oesophagus, may be treated with a transhiatal resection, whereas squamous cell carcinomas, which are typically found in the middle and the upper third, require a transthoracic approach. Since overall survival after surgery alone is poor, multimodality approaches have been developed. At least for patients with locally advanced tumors, surgery alone can no longer be advocated as routine treatment. Nowadays, scientific interest is focused on tumor response to induction radiochemotherapy. A neoadjuvant approach includes the early and accurate assessment of clinical response, optimally performed by repeated PET-CT imaging and endoscopic ultrasound, which may permit early adaption of the therapeutic concept. Patients with SCC that show clinical response by PET CT are considered to have a better prognosis, regardless of whether surgery will be performed or not. In non-responding patients salvage surgery improves survival, especially if complete resection is achieved.
\end{abstract}

\section{Surgery}

In Western countries, the recent epidemiological shift from squamous cell carcinoma to adenocarcinoma arising in Barrett's metaplasia has led to an increasing referral of patients with early oesophageal tumours detected during endoscopic surveillance [1]. Squamous cell carcinoma (SCC) is associated with low socioeconomic status [2], active tobacco and alcohol abuse, malnutrition, liver dysfunction, pulmonary co-morbidities, and second malignancies [3].

Patients with adenocarcinoma (AC) are characterized by co-morbidities such as coronary heart disease and a higher median age [4]. AC is predominantly (94\%) located in the lower third of the oesophagus, whereas $51 \%$ of SCC are found in the middle third and only $36 \%$ in the lower third. Moreover, a better prognosis with a

\footnotetext{
* Correspondence: maria.wolf@med.uni-muenchen.de

${ }^{1}$ Klinik und Poliklinik für Strahlentherapie und Radioonkologie, Ludwig-

Maximilians Universität München, Germany

Full list of author information is available at the end of the article
}

significantly higher overall survival after resection of AC than SCC was reported in some studies [5-7] whereas a SEER database review of 4752 patients showed no difference [8]. However, the majority of patients still present with advanced disease and up to two thirds are inoperable at the time of diagnosis.

Complete resection (R0), N- and T-stage are independent prognostic factors for SCC. Patients are categorised in risk groups by Karnofsky Performance Scale (KPS), cardiac function, liver and lung parameters [9]. Preoperative improvement of nutritional status, abstention from tobacco and alcohol can decrease the perioperative risk. Patients with SCC of the cervical oesophagus, T1 2, with low surgical risk according to Bartels et al. [9], can be treated by a limited resection including regional lymphadenectomy and reconstruction using a free jejunal loop with microsurgical vessel anastomoses, whereas T3-4 patients are treated with neoadjuvant radiochemotherapy. Patients with a high perioperative risk get definitive radiochemotherapy regardless of T-stage. In 
the low risk situation, T1-2 tumours located in the middle and lower third of the oesophagus are treated with transthoracic en-bloc-oesophagectomy with two-field lymphadenectomy and reconstruction with a gastric tube. Use of the colon as an esophageal substitute is reserved to patients with previous gastric resection. In patients with T3-4 tumours the same surgical strategy is chosen, if possible after preoperative radiochemotherapy. Again, for patients with higher perioperative risk definitive radiochemotherapy is the treatment of choice. For AC R0, $\mathrm{T}$ - and $\mathrm{N}$-stage are also independent prognostic markers. Grading is more advantageous in carcinoma of the gastro-oesophageal junction (GEJ) I than GEJ II/III, with $80 \%$ of intestinal metaplasia (Barrett's oesophagus) being found in GEJ I [6]. The surgical procedure of choice for GEJ I is subtotal oesophagectomy with proximal gastric resection and a two-field lymphadenectomy, whereas GEJ II/III is treated by transhiatal extended gastric resection and oesophagojejunostomy. For early GEJ I-III a transabdominal limited resection of the distal oesophagus and the proximal stomach with interposition of small intestine (Merendino procedure) can be performed. When transthoracic oesophagectomy (TTE) is compared to the transhiatal oesophagectomy (THE) for adenocarcinoma of the mid and distal oesophagus, no significant difference in overall survival can be observed, but a tendency towards better 5-year survival for TTE in GEJ I and better locoregional control with limited lymphnode invasion have been reported [10,11]. Kato et al. showed a significantly higher overall survival in 3field versus 2-field lymphadenectomy [12], whereas a randomised trial showed no benefit [13]. Cervical lymphadenectomy seems to be useful in carcinomas located in the cervical and upper third of the oesophagus $[13,14]$. Transhiatal oesophagectomy is indicated in patients with high pulmonary risk since it decreases early morbidity and mortality but has a trend to worse long term survival. With either a 3 -field or a 2 -field approach 5 -year overall survival rates of $20 \%$ can be achieved [15]. Hence, oesophagectomy is a complex operation that entails a two or three-field approach depending on the site of tumor, clinical staging, and Karnofsky performance status. Although overall postoperative mortality has decreased to less than $5 \%$ in high-volume centers [16], anastomotic and respiratory failures are still frequent [11]. In the past three decades surgery has developed from transhiatal oesophagectomy [17] to video-assisted surgery $[18,19]$. Laparoscopy has provided the opportunity of minimally invasive surgical staging [20] and gastric mobilisation with D2 lymphadenectomy extended to the lower mediastinal compartment $[21,22]$. Furthermore, it was shown that hybrid operations combining laparoscopy and right thoracotomy could be advantageous in regards to respiratory function [23]. A three-stage thoracoscopic oesophagectomy with cervical anastomosis may represent a better minimally invasive surgical option in SCC patients $[24,25]$. Expected advantages of minimal access techniques include a decrease in postoperative pain, inflammatory cytokine production, cardiopulmonary complications, blood loss, and the length of hospital stay. Although short and medium-term efficacy of these procedures have been proven [26-28], results are still inconclusive. As multicentre studies are not available and because of problems with standardization of such complex procedures, the effectiveness of minimal access oesophageal surgery is difficult to demonstrate.

In summary, from a surgical point of view, $\mathrm{AC}$ and SCC need separate therapeutic strategies for which accurate patient selection (staging, evaluation of co-morbidities) is indispensable. Minimally invasive oesophageal surgery is evolving and may become increasingly important. Still, it is hard to imagine that the management of oesophageal cancer will merely be based on improved surgery. Instead, surgeons should be ready for a new scenario, which comprises biological tumour staging and targeted therapies combined with neoadjuvant radiochemotherapy.

\section{Radiochemotherapy}

For the past three decades combined modality treatment for cancer of the oesophagus has been investigated in a number of studies with the intention to improve longterm outcome. Because of disappointing results of the intergroup study 0113 [29] perioperative treatment for oesophageal cancer has been a matter of debate for a long time. Nowadays we know that the non-stratified mixture of patients led to a bias. Meanwhile, six metaanalyses show the value of perioperative radiochemotherapy [30-35].

\subsection{Radiochemotherapy as definitive treatment}

One of the first studies analyzing the efficacy of radiochemotherapy as definitive treatment was the RTOG 85-01 trial $[36,37]$, which revealed the superiority of radiochemotherapy compared to radiotherapy alone in regards to 5-years overall survival. Acute toxicity was higher in the combined treatment arm, yet no difference in long term toxicity could be observed. This trial still exerts a major influence in clinical practice. A meta-analysis by Wong including 19 (11 concomitant radiochemotherapy, 8 sequential) trials that compare radiochemotherapy versus radiotherapy alone concludes that concomitant radiochemotherapy is better than sequential radiochemotherapy in regards to overall survival, disease free survival and local control [38]. The only study that compared definitive radiochemotherapy to surgery alone found no statistically significant 
difference for overall survival and disease free survival [39] showing, that neither of the two treatment modalities is superior. This study was criticized for ethical inadequacies (e.g.: no informed consent) and therefore published only with reserve. Although the intergroup dose escalation study (INT 123) found no benefit for an increase from 50.4 to $64.8 \mathrm{~Gy}$, a moderate dose escalation seems useful $[40,41]$.

\subsection{Radiochemotherapy in multimodal treatment approaches}

Several studies and three metaanalyses showed a statistically significant survival benefit for preoperative radiochemotherapy plus surgery versus surgery alone $[31,32,35,42,43]$. Fiorica found that the effect of preoperative radiochemotherapy is even more pronounced in patients with adenocarcinoma [35]. A metaanalysis performed by Gebski et al. revealed that both SCC and adenocarcinoma benefit from preoperative radiochemotherapy [31]. The problem with some of these trials is that - by current standards - low to moderate doses were used because of crude methods of radiation planning and delivery at the time. Three other metaanalyses showed no significant survival advantage for preoperative radiochemotherapy $[33,34,44]$. Due to this inconclusiveness we hypothesize that overall survival alone may be an insufficient parameter to describe the effectiveness of preoperative radiochemotherapy. In an interesting study Berger et al. correlate overall survival with complete pathological response (pCR). The 5-year survival of patients who achieved $\mathrm{pCR}$ after preoperative radiochemotherapy was almost 50\% [45]. The second independent predictive marker for overall survival was complete resection (R0). Thus, the question arises whether $\mathrm{pCR}$ is an integrative biomarker for generally better prognosis or a pre-requisite for more effective surgery, in both cases better outcome can be expected. This is confirmed by two other studies [46,47].

The trials performed by Stahl et al. and Bedenne et al. showed improved local control with radiochemotherapy followed by surgery compared to radiochemotherapy alone. An important result of these studies is that patients with tumour response to induction chemo (radio)therapy constitute a favorable prognostic subgroup. Nevertheless, treatment related mortality in the surgery arm was $12.8 \%$ as opposed to $3.5 \%$ with radiochemotherapy only $[48,49]$. These studies suggest that tumour response to induction radiochemotherapy might help to identify patients with good prognosis, regardless of whether surgery will be performed or not. In these patients surgery can no longer be recommended as routine treatment $[49,50]$. But in the group of non-responders surgery improved survival, especially if complete resection has been achieved. Future studies are warranted to increase the number of responders to induction treatment and to investigate dose escalation regimens. In these studies the integration of functional imaging methods for response evaluation is indispensable.

\section{PET/CT for staging and response prediction}

Endoscopic ultrasound and computer tomography (CT) are primarily used for the assessment of local tumour invasion and locoregional lymph node involvement. For detection of local lymph node metastases, Positron emission tomography (PET) with the glucose analogue 2'-[18F]-fluoro-2'-deoxy-D-glucose (FDG) has a limited sensitivity and specificity of $57 \%$ (95\% CI, $43 \%-70 \%)$ and 85\% (95\% CI, 76\%-95\%), respectively [51]. Therefore, in the detection of locoregional disease, PET appears to be inferior to endoscopic ultrasonography. But for the purpose of M-staging FDG-PET is very useful with a sensitivity and specificity of $71 \%$ (95\% CI, 62\%-79\%) and 93\% (95\% CI, 89\%-97\%) [51,52], which is crucial for the differentiation between locoregional and systemic disease. In adenocarcinomas of the oesophago-gastric junction (GEJ), FDG has been established and validated as a surrogate marker for therapy response assessment. A number of studies showed that FDG-PET allows prediction of response and prognosis whereas in other studies FDG-PET was not predictive for response and prognosis [53]. The MUNICON trial is a unicentre study, which showed that a PET guided treatment algorithm in patients with adenocarcinoma of the oesophago-gastric junction is feasible [54]. The results of this study are important concerning the individualization of multimodal treatment approaches. The use of FDG PET and $\mathrm{PET} / \mathrm{CT}$ for therapy monitoring in oesophageal cancer is the subject of intense discussion, underlining the need for randomized multicentre studies.

\section{Summary}

In summary, the following therapeutic strategies can be proposed: surgical resection for stage I and IIA, neoadjuvant chemotherapy (adenocarcinomas) or radiochemotherapy (squamous cell or adenocarcinomas) plus surgery for stage IIB. In locally advanced oesophageal cancer (stage III) - if surgery is potentially possible neoadjuvant radiochemotherapy should be followed by surgery in patients with adenocarcinomas or those patients with SCC without morphological response after chemo(radio)therapy. For responders with SCC we consider completion of radiochemotherapy to be the most appropriate treatment option. Future tasks comprise improved delivery of radiochemotherapy by integration of techniques such as IMRT to reduce toxicity, a better understanding of tumour response by research on molecular profiles to predict $\mathrm{pCR}$ and finally clinical 
evaluation of neoadjuvant treatment by PET-CT imaging combined with endoscopic ultrasound [50].

\section{Author details}

${ }^{1}$ Klinik und Poliklinik für Strahlentherapie und Radioonkologie, LudwigMaximilians Universität München, Germany. ${ }^{2}$ Klinik für Internistische Onkologie und Hämatologie, Kliniken Essen-Mitte, Germany. ${ }^{3}$ Klinik und Poliklinik für Nuklearmedizin, Klinikum rechts der Isar, Technische Universität München, Germany. ${ }^{4}$ Klinik und Poliklinik für Nuklearmedizin, Universitätsklinikum Rostock, Germany. ${ }^{5}$ Department of Medical and Surgical Sciences, Division of General Surgery, IRCCS, Policlinico San Donato, University of Milan School of Medicine, Milano, Italy. ${ }^{6}$ Chirurgische Klinik und Poliklinik, Ludwig-Maximilians Universität München, Germany.

\section{Authors' contributions}

MCW, CB1, LB: wrote and compiled the chapter surgery, responsible for content. MCW, MS, CB2, FZ wrote and compiled the chapter radiochemotherapy, responsible for content. BJK: wrote the chapter PET/CT, responsible for content. MCW, FZ: wrote the abstract and the summary, responsible for content. MCW, FZ, CB2: participated at the revision. All authors read and approved the final manuscript.

\section{Competing interests}

The authors declare that they have no competing interests.

Received: 3 February 2011 Accepted: 26 May 2011

Published: 26 May 2011

\section{References}

1. Incarbone R, Bonavina L, Saino G, Bona D, Peracchia A: Outcome of esophageal adenocarcinoma detected during endoscopic biopsy surveillance for Barrett's esophagus. Surg Endosc 2002, 16(2):263-266.

2. Brown LM, Hoover R, Silverman D, Baris D, Hayes R, Swanson GM, Schoenberg J, Greenberg R, Liff J, Schwartz A, et al: Excess incidence of squamous cell esophageal cancer among US Black men: role of social class and other risk factors. Am J Epidemiol 2001, 153(2):114-122.

3. Fukuzawa K, Noguchi Y, Yoshikawa T, Saito A, Doi C, Makino T, Takanashi Y, Ito T, Tsuburaya A: High incidence of synchronous cancer of the oral cavity and the upper gastrointestinal tract. Cancer Lett 1999, 144(2):145-151.

4. Bonavina L, Incarbone R, Saino G, Clesi P, Peracchia A: Clinical outcome and survival after esophagectomy for carcinoma in elderly patients. Dis Esophagus 2003, 16(2):90-93.

5. Siewert JR, Feith M, Stein HJ: Esophagectomy as therapeutic principle for squamous cell esophageal cancer. Chirurg 2005, 76(11):1033-1043.

6. Siewert JR, Stein HJ, Feith M, Bruecher BL, Bartels H, Fink U: Histologic tumor type is an independent prognostic parameter in esophageal cancer: lessons from more than 1,000 consecutive resections at a single center in the Western world. Ann Surg 2001, 234(3):360-367, discussion 368-369.

7. Stein HJ, Feith M, Bruecher BL, Naehrig J, Sarbia M, Siewert JR: Early esophageal cancer: pattern of lymphatic spread and prognostic factors for long-term survival after surgical resection. Ann Surg 2005, 242(4):566-573, discussion 573-565.

8. Chang DTCC, Shen J, Su Z, Koong AC: Treatment of esophageal cancer based on histology: a surveillance epidemiology and end results analysis. Am J Clin Oncol 2009, 32(4):405-410.

9. Bartels H, Stein HJ, Siewert JR: Preoperative risk analysis and postoperative mortality of oesophagectomy for resectable oesophageal cancer. Br J Surg 1998, 85(6):840-844.

10. Hulscher JB, van Sandick JW, de Boer AG, Wijnhoven BP, Tijssen JG, Fockens P, Stalmeier PF, ten Kate FJ, van Dekken H, Obertop H, et al: Extended transthoracic resection compared with limited transhiatal resection for adenocarcinoma of the esophagus. N Engl J Med 2002, 347(21):1662-1669.

11. Omloo JM, Lagarde SM, Hulscher JB, Reitsma JB, Fockens P, van Dekken $H$, Ten Kate FJ, Obertop H, Tilanus HW, van Lanschot JJ: Extended transthoracic resection compared with limited transhiatal resection for adenocarcinoma of the mid/distal esophagus: five-year survival of a randomized clinical trial. Ann Surg 2007, 246(6):992-1000, discussion 10001001.

12. Kato H, Fukuchi M, Miyazaki T, Nakajima M, Tanaka N, Inose T, Kimura H, Faried A, Saito K, Sohda M, et al: Surgical treatment for esophageal cancer. Current issues. Dig Surg 2007, 24(2):88-95.

13. Nishihira T, Hirayama K, Mori S: A prospective randomized trial of extended cervical and superior mediastinal lymphadenectomy for carcinoma of the thoracic esophagus. Am J Surg 1998, 175(1):47-51.

14. Altorki N, Skinner D: Should en bloc esophagectomy be the standard of care for esophageal carcinoma? Ann Surg 2001, 234(5):581-587.

15. Hulscher JB, Tijssen JG, Obertop H, van Lanschot JJ: Transthoracic versus transhiatal resection for carcinoma of the esophagus: a meta-analysis. Ann Thorac Surg 2001, 72(1):306-313.

16. Birkmeyer JD, Stukel TA, Siewers AE, Goodney PP, Wennberg DE, Lucas FL: Surgeon volume and operative mortality in the United States. N Engl J Med 2003, 349(22):2117-2127.

17. Orringer MB, Sloan H: Esophagectomy without thoracotomy. J Thorac Cardiovasc Surg 1978, 76(5):643-654

18. Buess $G$, Naruhn M, Motzung T, Mentges B, Becker HD: Training program for minimally invasive surgery. Chirurg 1991, 62(4):276-283.

19. Cuschieri A, Shimi S, Banting S: Endoscopic oesophagectomy through a right thoracoscopic approach. J R Coll Surg Edinb 1992, 37(1):7-11.

20. Bonavina L, Incarbone R, Lattuada E, Segalin A, Cesana B, Peracchia A: Preoperative laparoscopy in management of patients with carcinoma of the esophagus and of the esophagogastric junction. J Surg Oncol 1997, 65(3):171-174.

21. DePaula AL, Hashiba K, Ferreira EA, de Paula RA, Grecco E: Laparoscopic transhiatal esophagectomy with esophagogastroplasty. Surg LaparosC Endosc 1995, 5(1):1-5.

22. Bonavina $L$, Incarbone $R$, Bona $D$, Peracchia A: Esophagectomy via laparoscopy and transmediastinal endodissection. I Laparoendosc Adv Surg Tech A 2004, 14(1):13-16.

23. Bonavina L, Bona D, Binyom PR, Peracchia A: A laparoscopy-assisted surgical approach to esophageal carcinoma. J Surg Res 2004, 117(1):52-57.

24. Biere SS, Maas KW, Bonavina L, Roig Garcia J, van Berge Henegouwen MI, Rosman C, Sosef MN, de Lange ES, Bonjer HJ, Cuesta MA, et al: Traditional invasive vs. minimally invasive esophagectomy: a multi-centered, randomized trial (TIME-trial). BMC Surg 2011, 11(1):2.

25. Bonavina L: Selected commentary to "Fifty-five minimally invasive esophagectomies: a single center experience". Eur Surg 2009, 41(4):194-198.

26. Palanivelu C, Prakash A, Senthilkumar R, Senthilnathan P, Parthasarathi R, Rajan PS, Venkatachlam S: Minimally invasive esophagectomy: thoracoscopic mobilization of the esophagus and mediastinal lymphadenectomy in prone position-experience of 130 patients. J Am Coll Surg 2006, 203(1):7-16.

27. Luketich JD, Alvelo-Rivera M, Buenaventura PO, Christie NA, McCaughan JS, Litle VR, Schauer PR, Close JM, Fernando HC: Minimally invasive esophagectomy: outcomes in 222 patients. Ann Surg 2003, 238(4):486-494, discussion 494-485.

28. Taguchi S, Osugi H, Higashino M, Tokuhara T, Takada N, Takemura M, Lee S, Kinoshita H: Comparison of three-field esophagectomy for esophageal cancer incorporating open or thoracoscopic thoracotomy. Surg Endosc 2003, 17(9):1445-1450.

29. Kelsen DP, Ginsberg R, Pajak TF, Sheahan DG, Gunderson L, Mortimer J, Estes N, Haller DG, Ajani J, Kocha W, et al: Chemotherapy followed by surgery compared with surgery alone for localized esophageal cancer. $N$ Engl J Med 1998, 339(27):1979-1984.

30. Greer SE, Goodney PP, Sutton JE, Birkmeyer JD: Neoadjuvant chemoradiotherapy for esophageal carcinoma: a meta-analysis. Surgery 2005, 137(2):172-177.

31. Gebski V, Burmeister B, Smithers BM, Foo K, Zalcberg J, Simes J: Survival benefits from neoadjuvant chemoradiotherapy or chemotherapy in oesophageal carcinoma: a meta-analysis. Lancet Oncol 2007, 8(3):226-234.

32. Urschel JD, Vasan $\mathrm{H}$ : A meta-analysis of randomized controlled trials that compared neoadjuvant chemoradiation and surgery to surgery alone for resectable esophageal cancer. Am J Surg 2003, 185(6):538-543.

33. Kaklamanos IG, Walker GR, Ferry K, Franceschi D, Livingstone AS: Neoadjuvant treatment for resectable cancer of the esophagus and the gastroesophageal junction: a meta-analysis of randomized clinical trials. Ann Surg Oncol 2003, 10(7):754-761. 
34. Malthaner RA, Wong RK, Rumble RB, Zuraw L: Neoadjuvant or adjuvant therapy for resectable esophageal cancer: a systematic review and meta-analysis. BMC medicine 2004, 2:35.

35. Fiorica F, Di Bona D, Schepis F, Licata A, Shahied L, Venturi A, Falchi AM, Craxi A, Camma C: Preoperative chemoradiotherapy for oesophageal cancer: a systematic review and meta-analysis. Gut 2004, 53(7):925-930.

36. Herskovic A, Martz K, al-Sarraf M, Leichman L, Brindle J, Vaitkevicius V, Cooper J, Byhardt R, Davis L, Emami B: Combined chemotherapy and radiotherapy compared with radiotherapy alone in patients with cancer of the esophagus. N Engl J Med 1992, 326(24):1593-1598.

37. Cooper JS, Guo MD, Herskovic A, Macdonald JS, Martenson JA Jr, AlSarraf M, Byhardt R, Russell AH, Beitler JJ, Spencer S, et al: Chemoradiotherapy of locally advanced esophageal cancer: long-term follow-up of a prospective randomized trial (RTOG 85-01). Radiation Therapy Oncology Group. JAMA 1999, 281(17):1623-1627.

38. Wong R, Malthaner R: Combined chemotherapy and radiotherapy (without surgery) compared with radiotherapy alone in localized carcinoma of the esophagus. Cochrane Database Syst Rev 2006, , 1 : CD002092.

39. Chiu PW, Chan AC, Leung SF, Leong HT, Kwong KH, Li MK, Au-Yeung AC, Chung SC, Ng EK: Multicenter prospective randomized trial comparing standard esophagectomy with chemoradiotherapy for treatment of squamous esophageal cancer: early results from the Chinese University Research Group for Esophageal Cancer (CURE). J Gastrointest Surg 2005, 9(6):794-802.

40. Minsky BD, Pajak TF, Ginsberg RJ, Pisansky TM, Martenson J, Komaki R, Okawara G, Rosenthal SA, Kelsen DP: INT 0123 (Radiation Therapy Oncology Group 94-05) phase III trial of combined-modality therapy for esophageal cancer: high-dose versus standard-dose radiation therapy. J Clin Oncol 2002, 20(5):1167-1174.

41. Berger B, Belka C: Evidence-based radiation oncology: oesophagus. Radiother Oncol 2009, 92(2):276-290

42. Walsh TN, Noonan N, Hollywood D, Kelly A, Keeling N, Hennessy TP: A comparison of multimodal therapy and surgery for esophageal adenocarcinoma. N Engl J Med 1996, 335(7):462-467.

43. Tepper J, Krasna MJ, Niedzwiecki D, Hollis D, Reed CE, Goldberg R, Kiel K, Willett $C$, Sugarbaker D, Mayer R: Phase III trial of trimodality therapy with cisplatin, fluorouracil, radiotherapy, and surgery compared with surgery alone for esophageal cancer: CALGB 9781. J Clin Oncol 2008, 26(7):1086-1092.

44. Arnott SJ, Duncan W, Gignoux M, Girling DJ, Hansen HS, Launois B, Nygaard K, Parmar MK, Roussel A, Spiliopoulos G, et al: Preoperative radiotherapy in esophageal carcinoma: a meta-analysis using individual patient data (Oesophageal Cancer Collaborative Group). Int J Radiat Oncol Biol Phys 1998, 41(3):579-583.

45. Berger AC, Farma J, Scott WJ, Freedman G, Weiner L, Cheng JD, Wang H, Goldberg M: Complete response to neoadjuvant chemoradiotherapy in esophageal carcinoma is associated with significantly improved survival. J Clin Oncol 2005, 23(19):4330-4337.

46. Burmeister BH, Smithers BM, Gebski V, Fitzgerald L, Simes RJ, Devitt P, Ackland S, Gotley DC, Joseph D, Millar J, et al: Surgery alone versus chemoradiotherapy followed by surgery for resectable cancer of the oesophagus: a randomised controlled phase III trial. Lancet Oncol 2005, 6(9):659-668.

47. Stuschke M, Sarbia M: Neoadjuvante Radiochemotherapie und Responseprädiktion. Onkologe 2004, 10:1179-1190.

48. Bedenne L, Michel P, Bouche O, Milan C, Mariette C, Conroy T, Pezet D, Roullet B, Seitz JF, Herr JP, et al: Chemoradiation followed by surgery compared with chemoradiation alone in squamous cancer of the esophagus: FFCD 9102. J Clin Oncol 2007, 25(10):1160-1168.

49. Stahl M, Stuschke M, Lehmann N, Meyer HJ, Walz MK, Seeber S, Klump B, Budach W, Teichmann R, Schmitt M, et al: Chemoradiation with and without surgery in patients with locally advanced squamous cell carcinoma of the esophagus. J Clin Oncol 2005, 23(10):2310-2317.

50. Mariette C, Piessen G, Triboulet JP: Therapeutic strategies in oesophageal carcinoma: role of surgery and other modalities. Lancet Oncol 2007, 8(6):545-553.

51. van Vliet EP, Heijenbrok-Kal MH, Hunink MG, Kuipers EJ, Siersema PD: Staging investigations for oesophageal cancer: a meta-analysis. $\mathrm{Br} J$ Cancer 2008, 98(3):547-557.
52. Fletcher JW, Djulbegovic B, Soares HP, Siegel BA, Lowe VJ, Lyman GH, Coleman RE, Wahl R, Paschold JC, Avril N, et al: Recommendations on the use of 18F-FDG PET in oncology. J Nucl Med 2008, 49(3):480-508.

53. Krause BJ, Herrmann $K$, Wieder H, zum Buschenfelde CM: 18F-FDG PET and 18F-FDG PET/CT for assessing response to therapy in esophageal cancer. J Nucl Med 2009, 50(Suppl 1):895-965.

54. Lordick F, Ott K, Krause BJ, Weber WA, Becker K, Stein HJ, Lorenzen S,

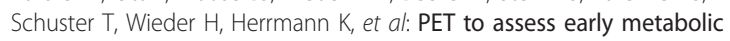
response and to guide treatment of adenocarcinoma of the oesophagogastric junction: the MUNICON phase II trial. Lancet Oncol 2007, 8(9):797-805.

doi:10.1186/1748-717X-6-55

Cite this article as: Wolf et al:: Curative treatment of oesophageal carcinoma: current options and future developments. Radiation Oncology $20116: 55$.

\section{Submit your next manuscript to BioMed Central and take full advantage of:}

- Convenient online submission

- Thorough peer review

- No space constraints or color figure charges

- Immediate publication on acceptance

- Inclusion in PubMed, CAS, Scopus and Google Scholar

- Research which is freely available for redistribution

Submit your manuscript at www.biomedcentral.com/submit
Biomed Central 